\title{
PERENCANAAN SALURAN PRIMER PARIT TOKAYA DENGAN KEMAMPUAN SWA PURIFIKASI SALURAN TERHADAP BEBAN PENCEM AR ORGANIK
}

\author{
Marita Purnama Sari ${ }^{1}$, Winardi Yusuf ${ }^{2}$, Kiki Prio Utomo ${ }^{3}$ \\ Program Studi Teknik Lingkungan, Universitas Tanjungpura, Pontianak \\ Email: maritaps@yahoo.com
}

\begin{abstract}
ABSTRAK
Hasil pemantauan kualitas air Parit Tokaya oleh BLH Kota Pontianak pada tahun 2010 dan 2011 menunjukan nilai BOD yang telah melebihi nilai maksimum menurut baku mutu kelas dua menurut Peraturan Pemerintah No. 82 tahun 2001. Keadaan ini menandakan jika Parit Tokaya telah tercemar oleh limbah domestik dan air tidak dapat digunakan lagi oleh masyarakat setempat untuk aktivitas seperti M CK. Perbaikan kualitas air Parit Tokaya dapat dilakukan dengan beberapa cara, salah satunya adalah dengan meningkatkan kemampuan swa purifikasi saluran. Untuk merancang cara meningkatkan kemampuan swa purifikasi Parit Tokaya perlu diketahui nilai DO lapangan. Swa purifikasi dilakukan dengan memperbaiki koefisien rearasi (Kr), yang dapat dicapai dengan mengubah dimensi saluran, menggunakan alat atau bangunan. Kondisi Parit Tokaya tidak memungkinkan untuk mengubah dimensi saluran atau menggunakan bangunan. Sehingga metode peningkatan swa purifikasi yang mungkin digunakan adalah menggunakan alat yang dapat mensuplai oksigen ke dalam air atau yang disebut aerator. Hasil pengukuran memberikan nilai DO lapangan bervariasi antara 0,84-4,74 mg/l pada kondisi surut dan 1,61-6,61 mg/l pada kondisi pasang. Peningkatan swa purifikasi diharapkan dapat meningkatkan nilai DO di dalam Parit Tokaya minimal $2 \mathrm{mg} / \mathrm{l}$. Jumlah aerator yang diperlukan untuk memperbaiki kualitas air Parit Tokaya adalah 35 buah. Aerator dipasang sepanjang Parit Tokaya dengan jarak antara aerator adalah $150 \mathrm{~m}$. Sedangkan kapasitas pompa aerator yang digunakan adalah $10 \mathrm{~W} / \mathrm{m}^{3}-90$ $\mathrm{W} / \mathrm{m}^{3}$.
\end{abstract}

Kata kunci : Parit Tokaya, swa purifikasi, aerator

\begin{abstract}
The results of water quality monitoring in Parit Tokaya conducted by BLH Pontianak in 2010 and 2011 showed that BOD value have exceeded the maximum value according to the two-class quality standards according PP No. 82 th 2001. It is an indication that Parit Tokaya been polluted by domestic waste and water can not be used by the local comunity for activities such as toillets. Improve water quality in Parit Tokaya, it's needed to enhanced self purification. Self-purificationis achievedby fixing the reaeration coefficient ( $\mathrm{Kr})$, which can be achieved by changing the dimensions of the channel or using the building. Self purification can be enhanced using aerator that will increase oxygen dissolved in water. The results of field measurements provide value DO vary between 0,84 to $4,74 \mathrm{mg} / \mathrm{I}$ at low tide conditions and from 1,61 to $6,61 \mathrm{mg} /$ I on tidal conditions. The increase in self-purification is expected to increase the value of DO in the Parit Tokaya at $2 \mathrm{mg} / \mathrm{I}$. The number of aerators required to improve water quality Parit Tokaya is 35 pieces. Aerators installed along the Parit Tokaya with distance between the aerators is $150 \mathrm{~m}$. While capacity aerator pump used is $10 \mathrm{w} / \mathrm{m}^{3}-90 \mathrm{w} / \mathrm{m}^{3}$.
\end{abstract}

Key word: Parit Tokaya, self-purification, aerator

\section{PENDAHULUAN}

Parit Tokaya merupakan salah satu saluran drainase primer yang ada di Kecamatan Pontianak Selatan, Kota Pontianak yang berfungsi mengalirkan air limpasan permukaan serta air buangan dari kawasan pemukiman dan perdagangan yang berada di dalam daerah pengalirannya. Saluran drainase Parit Tokaya bermuara di Sungai Kapuas Kecil dengan panjang saluran kurang lebih 6,7 km. Air di dalam Saluran Parit Tokaya juga dimanfaatkan oleh masyarakat yang bermukim di sekitarnya untuk keperluan mandi cuci dan kakus (M CK). 
Air limbah domestik dari kawasan pemukiman dan perdagangan di daerah pengaliran Saluran Parit Tokaya tidak diolah terlebih dahulu sebelum dibuang masuk ke dalam saluran. Berdasarkan hasil pemantauan kualitas air Parit Tokaya yang dilakukan oleh Badan Lingkungan Hidup Kota Pontianak tahun 2010 dan 2011, di beberapa titik sampling nilai parameter BOD (Biological Oxygen Demand) telah melebihi baku mutu sebagaimana ditunjukan pada Tabel 1.

Tabel 1. Nilai Parameter BOD di Saluran Parit Tokaya

\begin{tabular}{|c|c|c|}
\hline Tahun Pemantauan & $\begin{array}{c}\text { Baku Mutu untuk BOD } \\
(\mathrm{mg} / \mathrm{L})\end{array}$ & $\begin{array}{c}\text { Nilai BOD } \\
(\mathrm{mg} / \mathrm{L})\end{array}$ \\
\hline 2010 & 3 & $8-37$ \\
2011 & 3 & $9,4-40,2$ \\
\hline
\end{tabular}

Sumber: (BLH Kota Pontianak, 2010-2011)

Nilai BOD di dalam badan air menunjukan jumlah Oksigen yang diperlukan oleh mikroorganisme pada waktu melakukan penguraian hampir semua bahan organik yang terlarut dan sebagian yang tak terlarut. Berdasarkan data pemantauan kualitas air tersebut tampak jika air di dalam Saluran Parit Tokaya telah tercemar oleh buangan organik dari limbah domestik sehingga air tidak dapat digunakan lagi oleh masyarakat untuk aktivitas seperti MCK. Agar kondisi air di dalam Saluran Parit Tokaya menjadi lebih baik, perlu dilakukan berbagai upaya, diantaranya dengan meningkatkan kemampuan swa purifikasi badan air.

Tujuan dari perancangan yang dibuat adalah untuk:

1. Mengetahui kemampuan Saluran Parit Tokaya dalam melakukan swa purifikasi terhadap polutan yang membebaninya, serta mengetahui faktor-faktor yang mempengaruhinya.

2. Merancang sebuah cara atau alat yang digunakan untuk membantu memperbaiki proses swa purifikasi di dalam saluran Parit Tokaya tingkat pencemaran air dapat berkurang.

\section{DASAR TEORI}

A. Swa Purifikasi

Moersidik (2008) menjelaskan, swa purifikasi adalah pemurnian diri atau upaya pemurnian air dari zat pencemar yang terkandung di dalamnya oleh proses alamiah tanpa adanya pengaruh aktivitas manusia. Proses swa purifikasi dapat dipercepat dengan reaerasi. Reaerasi adalah proses terlarutnya oksigen dari udara ke dalam air. Reaerasi terjadi akibat adanya perbedaan konsentrasi oksigen di udara dan air. Faktor-faktor yang mempengaruhi kelarutan oksigen adalah kadar garam, tekanan udara dan temperatur.

\section{B. Aerator}

Aerator merupakan alat yang digunakan untuk menambah oksigen ke dalam air dengan cara mempercepat proses diffusi. Boyd (1979) menjelaskan bahwa aerator dapat digunakan untuk mempertahankan konsentrasi oksigen terlarut.

Aerator yang digunakan untuk perpindahan massa dari fase gas ke cair atau sebaliknya dibedakan dalam beberapa jenis sesuai dengan sifat operasinya, aerator udara terdifusi melakukan tranfer oksigen dari udara bertekanan yang diinjeksikan ke dalam air. Udara yang keluar dari difuser biasa berbentuk gelembung udara yang akan menyebabkan peningkatan turbulensi air.

\section{METODE PENELITIAN}

\section{A. Analisis hidrolik}

Analisis hidrolik Saluran Parit Tokaya dilakukan dengan mengukur dimensi saluran dan kecepatan aliran dengan menggunakan current meter, serta menghitung debit aliran dengan rumus;

$$
Q=A x v
$$


Dimana A merupakan luas penampang basah, dan $v$ adalah kecepatan aliran terukur dengan menggunakan current meter.

\section{B. Analisis kemampuan swa purifikasi saluran}

Analisis kemampuan swa purifikasi Saluran Parit Tokaya dilakukan dengan menghitung nilai $D$ eksisting dengan mensubsitusi nilai Kd dan Kr eksisting yang diperoleh dari nilai BOD dan DO eksisting dengan persamaan berikut:

$$
D=\frac{k_{d} L_{a}}{k_{\gamma}-k_{d}}\left(e^{-k_{a} a^{2}}-e^{-k_{r} t}\right)+D_{a}\left(e^{-k_{T} t}\right)
$$

Dimana:

$\mathrm{D}=$ defisit oksigen di dalam saluran terhadap waktu setelah pencampuran $\mathrm{mg} / \mathrm{L}$.

$\mathrm{L} \quad=$ BOD maksimum (ultimate) di dalam saluran setelah pencampuran, $\mathrm{mg} / \mathrm{L}$.

$\mathrm{Kd}=$ konstanta deoksigenasi, hari ${ }^{-1}$

$\mathrm{Kr}=$ konstanta reaerasi, hari ${ }^{-1}$.

$D_{a}=$ defisit oksigen di dalam saluran setelah pencampuran, $\mathrm{mg} / \mathrm{L}$.

$X=$ Jarak titik pencampuran, meter.

$\mathrm{V}=$ Kecepatan aliran, meter/detik.

\section{Ananlisis nilai Kd dan nilai Kr di Saluran Parit Tokaya}

Nilai Kr dapat diperkirakan dengan metode yang dianjurkan oleh O'Connor dan Dobbins (1958) dalam Davis dan Cornwell (1991).

$$
k_{r}\left(20^{\circ} \mathrm{C}\right)=3,93 \frac{V^{0,3}}{R^{2,3}}
$$

Dimana $\mathrm{V}$ adalah kecepatan rata-rata aliran air di saluran $(\mathrm{m} / \mathrm{dt})$ dan $\mathrm{R}$ adalah kedalaman rata-rata saluran $(m)$. Untuk suhu air yang berbeda digunakan hubungan yang ditemukan oleh Churcill:

$$
k_{r}\left(5^{\circ} \mathrm{C}\right)=k_{r}\left(20^{\circ} \mathrm{C}\right) \times 1,024^{(z-20)}
$$

Sedangkan nilai Kd perkiraan dengan metode dalam hydroscience (1971) sebagai berikut:

$$
k_{c i}\left(20^{\circ} C\right)=0_{r} 3\left(\frac{H}{B}\right)^{-0,43 a}
$$

Dimana $\mathrm{H}$ merupakan kedalaman air di dalam saluran (m). Kemudian untuk suhu air yang berbeda digunakan rumus yang ditemukan oleh Churcill dalam Davis dan Cornwell (1991). sebagai berikut:

$$
k_{d}\left(t^{\circ} \mathrm{C}\right)=k_{d}\left(20^{\circ} \mathrm{C}\right) \times 1,048^{(t-20)}
$$

\section{Analisis kecepatan aliran "Perlu" dengan meninjau nilai Kr}

Kecepatan aliran perlu adalah kecepatan aliran yang dibutuhkan untuk memaksimalkan proses swa purufikasi di Saluran Parit Tokaya. Analisis kecepatan aliran "Perlu" dilakukan dengan menghitung nilai $\mathrm{Kr}$ di lapangan melalui persamaan (3) dan persamaan (4). Dengan mengkonversi nilai $\mathrm{V}$ pada persamaan (4) sebagai $\vee$ (kecepatan aliran) dan $\mathrm{R}$ sebagai (h) kedalaman air di dalam saluran, maka akan diperoleh nilai v yang baru yang diperlukan untuk proses swa purifikasi saluran.

\section{E. Evaluasi kecepatan aliran "Izin"}

Analisis hidrolis teoritits di Saluran Parit Tokaya dihitung dengan menggunakan persamaan Manning sebagai berikut;

$$
v=\frac{1}{n} \times R^{2 / g} \times S^{1 / 2}
$$

\section{F. Penambahan Aerator}

Kapasitas aerator yang diperlukan untuk menyediakan Oksigen dapat dihitung dengan persamaan dibawah ini. 


$$
P=10^{3} x \frac{E^{3} a_{n}}{N V}
$$

Dimana, $P=$ Level daya, $\mathrm{W} / \mathrm{m}^{3}$

$\mathrm{RO}_{2}=$ Kecepatan pemnfaatan Oksigen, $\mathrm{kg} \mathrm{O}_{2} / \mathrm{jam}$

$\mathrm{V}=$ Volume bak aerasi, $\mathrm{m}^{3}$

$\mathrm{N} \quad=\quad$ Kinerja aerator yang diharapkan, $\mathrm{kg} \mathrm{O}_{2} / \mathrm{jam}$ berikut:

Kinerja aerator di Saluran Parit Tokaya yang diharapkan, dapat dihitung dengan persamaan

$$
N=N o \frac{\rho \sigma-\sigma}{9,17} \alpha \gamma
$$

\section{HASIL DAN PEMBAHASAN \\ A. Analisis Hidrolik}

Saluran Parit Tokaya adalah saluran dengan bentuk penampang segi empat dengan dasar saluran berupa tanah. Dinding saluran di bagian hulu masih berupa tanah, namun mendekati titik dua hingga ke titik 9 dinding saluran berupa turap kayu, sedangkan Jalan Tanjungpura sampai ke Muara Saluran Parit Tokaya dinding saluran sudah berturapkan beton. Data penampang hidrolik saluran disajikan dalam Tabel 2 dan Tabel 3(Pengukuran Lapangan, 2012).

Tabel 2. Data Hidrolik Penampang Saluran Parit Tokaya pada Kondisi Surut

\begin{tabular}{|c|l|r|r|r|r|r|r|}
\hline Titik & \multicolumn{1}{|c|}{ Lokasi Penelitian } & $\begin{array}{c}\mathbf{b} \\
(\mathbf{m})\end{array}$ & $\begin{array}{c}\mathbf{h} \\
(\mathbf{m})\end{array}$ & $\begin{array}{c}\mathbf{A} \\
\left(\mathbf{m}^{\mathbf{2}}\right)\end{array}$ & $\begin{array}{c}\mathbf{P} \\
(\mathbf{m})\end{array}$ & $\begin{array}{c}\mathbf{R} \\
(\mathbf{m})\end{array}$ & $\begin{array}{c}\mathbf{V} \\
(\mathbf{m} / \mathbf{s})\end{array}$ \\
\hline 1 & Pintu air di Jalan Purnama 2 & 5,8 & 0,85 & 4,93 & 7,50 & 0,66 & 0,04 \\
\hline 2 & Persimpangan Jalan Harapan Jaya & 5,9 & 0,68 & 4,01 & 7,26 & 0,55 & 0,26 \\
\hline 3 & Komplek Perumahan Purnama Agung 3 & 7,5 & 0,75 & 5,63 & 9,00 & 0,63 & 0,35 \\
\hline 4 & Persimpangan Jalan M. Sohor, Jalan Purnama & 8,0 & 0,75 & 6,00 & 9,50 & 0,63 & 0,35 \\
\hline 5 & Gelanggang Olahraga (GOR) & 11,4 & 0,70 & 7,98 & 12,80 & 0,62 & 0,10 \\
\hline 6 & Jalan Ahmad Yani & 9,5 & 0,60 & 5,70 & 10,70 & 0,53 & 0,49 \\
\hline 7 & Gang Sukur 5 & 10,0 & 0,70 & 7,04 & 11,45 & 0,61 & 0,54 \\
\hline 8 & Jalan Gajah Mada & 14,6 & 0,50 & 7,30 & 15,60 & 0,47 & 0,60 \\
\hline 9 & Di depan Pasar Flamboyan & 11,4 & 1,10 & 12,49 & 13,55 & 0,92 & 0,51 \\
\hline 10 & Jalan Tanjungpura & 11,9 & 0,90 & 10,78 & 13,78 & 0,78 & 0,31 \\
\hline 11 & Muara Parit Tokaya (Gg. Martapura 3) & 8,0 & 1,50 & 12,00 & 11,00 & 1,09 & 0,20 \\
\hline
\end{tabular}

Tabel 3. Data Hidrolik Penampang Saluran Parit Tokaya pada Kondisi Pasang

\begin{tabular}{|c|l|r|r|r|r|r|r|}
\hline Titik & \multicolumn{1}{|c|}{ Lokasi Penelitian } & $\begin{array}{c}\mathbf{b} \\
(\mathbf{m})\end{array}$ & $\begin{array}{c}\mathbf{h} \\
(\mathbf{m})\end{array}$ & $\begin{array}{c}\mathbf{A} \\
\left(\mathbf{m}^{2}\right)\end{array}$ & $\begin{array}{c}\mathbf{P} \\
(\mathbf{m})\end{array}$ & $\begin{array}{c}\mathbf{R} \\
(\mathbf{m})\end{array}$ & $\begin{array}{c}\mathbf{V} \\
(\mathbf{m} / \mathbf{s})\end{array}$ \\
\hline 1 & Pintu air di Jalan Purnama 2 & 5,8 & 0,75 & 4,35 & 7,30 & 0,60 & 0,04 \\
\hline 2 & Persimpangan Jalan Harapan Jaya & 5,9 & 0,90 & 5,31 & 7,70 & 0,69 & 0,06 \\
\hline 3 & Komplek Perumahan Purnama Agung 3 & 7,5 & 0,82 & 6,15 & 9,14 & 0,67 & 0,18 \\
\hline 4 & Persimpangan Jalan M. Sohor, Jalan Purnama & 8,0 & 1,25 & 10,00 & 10,50 & 0,95 & 0,21 \\
\hline 5 & Gelanggang Olahraga (GOR) & 11,4 & 1,20 & 13,68 & 13,80 & 0,99 & 0,07 \\
\hline 6 & Jalan Ahmad Yani & 9,5 & 1,15 & 10,93 & 11,80 & 0,93 & 0,24 \\
\hline 7 & Gang Sukur 5 & 10,0 & 1,36 & 13,67 & 12,77 & 1,07 & 0,19 \\
\hline 8 & Jalan Gajah Mada & 14,6 & 1,50 & 21,90 & 17,60 & 1,24 & 0,17 \\
\hline 9 & Di depan Pasar Flamboyan & 11,3 & 1,30 & 14,76 & 13,95 & 1,06 & 0,20 \\
\hline 10 & Jalan Tanjungpura & 11,9 & 1,68 & 20,13 & 15,34 & 1,31 & 0,12 \\
\hline 11 & Muara Parit Tokaya (Gg. Martapura 3) & 8,0 & 2,65 & 21,20 & 13,30 & 1,59 & 0,06 \\
\hline
\end{tabular}




\section{B. Analisis Kemampuan Swa Purifikasi Saluran Parit Tokaya}

Untuk mengetahui kemampuan swa purifikasi di Saluran Parit Tokaya maka dilakukan pengukuran nilai DO dan BOD pada saat pasang dan juga saat surut di saluran yang disajikan dalam Tabel 4.

Tabel 4. Kualitas Air Saluran Parit Tokaya untuk Parameter DO dan BOD

\begin{tabular}{|c|c|c|c|c|c|}
\hline \multirow[b]{2}{*}{ Titik } & \multirow[b]{2}{*}{ Lokasi Penelitian } & \multicolumn{2}{|c|}{ Kondisi Surut } & \multicolumn{2}{|c|}{ Kondisi Pasang } \\
\hline & & $\begin{array}{c}\text { DO Pengukuran } \\
(\mathrm{mg} / \mathrm{l})\end{array}$ & $\begin{array}{l}\mathrm{BOD}_{5} \\
(\mathrm{mg} / \mathrm{l})\end{array}$ & $\begin{array}{l}\text { D0 Pengukuran } \\
\text { (mg/l) }\end{array}$ & $\begin{array}{l}\mathrm{BOD}_{5} \\
(\mathrm{mg} / \mathrm{l})\end{array}$ \\
\hline 1 & Pintu air di Jalan Purnama 2 & 4,06 & 8,14 & 3,38 & 4,74 \\
\hline 2 & Persimpangan 3 Jalan Harapan Jaya & 4,74 & 3,39 & 2,88 & 5,08 \\
\hline 3 & Komplek Perumahan Purnama Agung 3 & 2,88 & 5,08 & 3,22 & 12,71 \\
\hline 4 & Persimpangan Jalan M. Sohor, Jalan Purnama & 2,88 & 7,63 & 2,03 & 6,1 \\
\hline 5 & Gelanggang Olahraga (GOR) & 2,71 & 8,14 & 1,61 & 9,66 \\
\hline 6 & Jalan Ahmad Yani & 2,71 & 5,42 & 3,53 & 7,12 \\
\hline 7 & Gang Sukur 5 di Jalan Veteran & 2,88 & 5,08 & 4,91 & 10,17 \\
\hline 8 & Jalan Gajah Mada & 3,22 & 7,63 & 6,61 & 1,36 \\
\hline 9 & Di depan Pasar Flamboyan & 0,84 & 14,24 & 5,59 & 3,56 \\
\hline 10 & Jalan Tanjungpura & 1,18 & 30,51 & 5,76 & 3,08 \\
\hline 11 & Muara Parit Tokaya (Gg. Martapura 3) & 0,84 & 28,47 & 6,44 & 1,69 \\
\hline
\end{tabular}

Sumber : (Hasil Uji Laboratorium Analisis Lingkungan Fakultas Pertanian, 2012)

Penetapan DO target merupakan salah satu upaya efektif dalam pengendalian pencemaran air. Dengan kondisi Saluran Parit Tokaya, maka target konsentrasi DO yang akan dicapai adalah dengan penambahan konsentrasi Oksigen sebanyak kurang lebih $2 \mathrm{mg} / \mathrm{l}$. Target DO yang diinginkan ada di Saluran Parit Tokaya adalah seperti yang ditampilkan pada Tabel 5 dari hasil analisis, 2012.

Tabel 5. DO pengukuran dan DO Target untuk Saluran Parit Tokaya.

\begin{tabular}{|c|c|c|c|c|c|}
\hline \multirow[b]{2}{*}{ Titik } & \multirow[b]{2}{*}{ Lokasi Sampel } & \multicolumn{2}{|c|}{ Kondisi Surut } & \multicolumn{2}{|c|}{ Kondisi Pasang } \\
\hline & & $\begin{array}{c}\text { DO Pengukuran } \\
(\mathrm{mg} / \mathrm{l})\end{array}$ & $\begin{array}{c}\text { DO } \\
\text { Target } \\
\text { (mg/l) }\end{array}$ & $\begin{array}{c}\text { DO Pengukuran } \\
\text { (mg/l) }\end{array}$ & $\begin{array}{c}\text { DO } \\
\text { Target } \\
\text { (mg/l) }\end{array}$ \\
\hline 1 & Pintu air di Jalan Purnama 2 & 4,06 & \pm 2 & 3,38 & \pm 2 \\
\hline 2 & Persimpangan 3 Jalan Harapan Jaya & 4,74 & \pm 2 & 2,88 & \pm 2 \\
\hline 3 & Komplek Perumahan Purnama Agung 3 & 2,88 & \pm 2 & 3,22 & \pm 2 \\
\hline 4 & Persimpangan Jalan M. Sohor, Jalan Purnama & 2,88 & \pm 2 & 2,03 & \pm 2 \\
\hline 5 & Gelanggang Olahraga (GOR) & 2,71 & \pm 2 & 1,61 & \pm 2 \\
\hline 6 & Jalan Ahmad Yani & 2,71 & \pm 2 & 3,53 & \pm 2 \\
\hline 7 & Gang Sukur 5 di Jalan Veteran & 2,88 & \pm 2 & 4,91 & \pm 2 \\
\hline 8 & Jalan Gajah Mada & 3,22 & \pm 2 & 6,61 & \pm 2 \\
\hline 9 & Di depan Pasar Flamboyan & 0,84 & \pm 2 & 5,59 & \pm 2 \\
\hline 10 & Jalan Tanjungpura & 1,18 & \pm 2 & 5,76 & \pm 2 \\
\hline 11 & Muara Parit Tokaya (Gg. M artapura 3) & 0,84 & \pm 2 & 6,44 & \pm 2 \\
\hline
\end{tabular}

Tabel 4 menunjukan hasil uji DO dan juga BOD di 11 titik pengambilan sampel air di Saluran Parit Tokaya yang berada di bawah baku mutu. Konsentrasi DO mengalami penurunan pada saat surut di bagian hilir saluran bahkan mendekati nol. Hal ini disebabkan adanya peningkatan beban pencemar yang kemudian terakumulasi di titik tersebut, sehingga Oksigen di perairan terus menerus digunakan untuk proses dekomposisi bahan organik hingga konsentrasi DO menurun secara drastis, dan juga rendahnya kecepatan aliran dan kurangnya pengenceran bahan pencemar turut memicu rendahnya konsentrasi Oksigen di dalam saluran. Pada saat surut peningkatan BOD terjadi di titik 9 yaitu tepat di area Pasar Flamboyan dimana konsentrasi DO hampir nol. Konsentrasi DO rendah 
hingga ke hilir saluran. Rendahnya konsentrasi Oksigen di hilir saluran juga dipicu oleh kedalaman saluran sehingga reaerasi sulit menembus lapisan air terdalam. Peristiwa-peristiwa yang terjadi di dalam saluran menunjukan bahwa proses swa purifikasi tidak terjadi pada kondisi surut.

Pada saat pasang konsentrasi DO sempat mengalami penurunan namun naik kembali mendekati bagian hulu saluran. Kondisi ini disebabkan pada saat pasang selain dari buangan domestik, air membawa buangan dari Pasar Flamboyan masuk menuju hulu sehingga konsentrasi DO menurun dalam perjalanan aliran air akibat aktifitas bakteri dalam melakukan dekomposisi buangan organik yang kemudian mencapai DO minimum di titik 5. Adanya aliran air yang masuk dari hilir saluran yaitu Sungai Kapuas Kecil turut menambah volume air di saluran untuk melakukan pengenceran air limbah buangan organik, sehingga proses swa purifikasi saluran terjadi. Dari hasil konsentrasi DO yang dihasilkan pada saat pasang dan surut, maka perbaikan konsentrasi oksigen di dalam saluran akan difokuskan pada saat terjadi surut karena Oksigen yang terlarut terus mengalami penurunan dan hampir mencapai titik kritis.

\section{Analisis nilai Kr dan nilai Kd di Saluran Parit Tokaya}

Pengukuran yang telah dilakukan di Saluran Parit Tokaya menghasilkan nilai Kr dan nilai Kd pada 11 titik sampel sebagaimana yang dicantumkan pada Tabel 6 dan Tabel 7.

Tabel 6. Hasil Pengukuran Kd dan Kr pada saat Surut di Saluran Parit Tokaya

\begin{tabular}{|c|c|c|c|c|c|c|c|c|c|c|c|}
\hline $\begin{array}{c}\mathbf{T} \\
\text { (hari) } \\
\end{array}$ & Titik & $\begin{array}{c}x \\
(\mathbf{k m}) \\
\end{array}$ & $\begin{array}{c}\mathbf{v} \\
(\mathbf{m} / \mathbf{s}) \\
\end{array}$ & $\begin{array}{l}\mathbf{h} \\
\text { (m) } \\
\end{array}$ & $\begin{array}{c}\text { Lo } \\
(\mathrm{mg} / \mathrm{l}) \\
\end{array}$ & $\begin{array}{c}\mathrm{Da} \\
(\mathrm{mg} / \mathrm{l}) \\
\end{array}$ & $\begin{array}{c}K d \\
\text { (1/hari) } \\
\end{array}$ & $\begin{array}{c}K r \\
\text { (1/hari) } \\
\end{array}$ & $\begin{array}{c}\text { D } \\
(\mathrm{mg} / \mathrm{l}) \\
\end{array}$ & $\begin{array}{c}\text { DO } \\
\text { lapangan } \\
(\mathrm{mg} / \mathrm{l}) \\
\end{array}$ & $\begin{array}{c}\text { DO } \\
\text { Saturasi } \\
(\mathrm{mg} / \mathrm{l}) \\
\end{array}$ \\
\hline 0,00 & 1 & 0,00 & 0,04 & 3,12 & 8,14 & 4,05 & 1,1 & 2,5 & 4,05 & 4,06 & 8,11 \\
\hline 0,0 & 2 & 1,45 & 0,26 & 0,68 & 3, & & 1 , & 1,0 & 3,1 & 4,7 & 7,69 \\
\hline 0,0 & 3 & 2, & & 0,75 & & 4 , & 1 & 0 , & & & 7,83 \\
\hline 0,03 & 4 & 0,80 & 0,35 & 0,75 & 7,6 & 4,95 & 1,2 & 0,2 & 5,16 & 2,8 & 7,83 \\
\hline 0,04 & 5 & 0,32 & 0,10 & 0,70 & 8,14 & 5,26 & 1,2 & 0,2 & 5,56 & 2,71 & 7,97 \\
\hline 0,01 & 6 & 0,48 & 0,49 & 0,60 & 5,42 & 5,26 & 1,3 & 0,9 & 5,29 & 2,71 & 7,97 \\
\hline 0,01 & 7 & 0,48 & 0,54 & 0,70 & 5,08 & 5,09 & 1,2 & 0,6 & 5,12 & 2,88 & 7,97 \\
\hline 0,01 & 8 & 0,32 & 0,60 & 0,50 & 7,63 & 4,89 & 1,3 & 0,7 & 4,93 & 3,22 & 8,11 \\
\hline 0,00 & 9 & 0,10 & 0,51 & 1,10 & 14,24 & 7,13 & 1,0 & 0,9 & 7,15 & 0,84 & 7,97 \\
\hline 0,01 & 10 & 0,32 & 0,31 & 0,90 & 30,51 & 6,79 & 1,1 & 0,9 & 7,10 & 1,18 & 7,97 \\
\hline 0,02 & 11 & 0,32 & 0,20 & 1,50 & 28,47 & 7,13 & 0,9 & 0,7 & 7,48 & 0,84 & 7,97 \\
\hline
\end{tabular}

Tabel 7. Hasil Pengukuran Kd dan Kr pada saat Pasang di Saluran Parit Tokaya

\begin{tabular}{|c|c|c|c|c|c|c|c|c|c|c|c|}
\hline $\begin{array}{c}\mathrm{T} \\
\text { (hari) }\end{array}$ & Titik & $\begin{array}{c}\mathbf{x} \\
(\mathbf{k m})\end{array}$ & $\begin{array}{c}\mathbf{v} \\
(\mathrm{m} / \mathrm{s})\end{array}$ & $\begin{array}{l}\mathbf{h} \\
(\mathbf{m})\end{array}$ & $\begin{array}{c}\text { Lo } \\
(\mathrm{mg} / \mathrm{l})\end{array}$ & $\begin{array}{c}\text { Da } \\
(\mathrm{mg} / \mathrm{l})\end{array}$ & $\begin{array}{c}K d \\
\text { (1/hari) }\end{array}$ & $\begin{array}{c}K r \\
\text { (1/hari) }\end{array}$ & $\begin{array}{c}\text { D } \\
(\mathrm{mg} / \mathrm{l})\end{array}$ & $\begin{array}{c}\text { DO } \\
\text { lapangan } \\
(\mathrm{mg} / \mathrm{l})\end{array}$ & $\begin{array}{c}\text { DO } \\
\text { Saturasi } \\
(\mathrm{mg} / \mathbf{l})\end{array}$ \\
\hline 0,00 & 1 & 0,00 & 0,04 & 0,75 & 4,75 & 4,88 & 1,1 & 7,1 & 4,88 & 3,38 & 8,26 \\
\hline 0,28 & 2 & 1,45 & 0,06 & 0,90 & 5,08 & 5,23 & 1,0 & 1,7 & 4,23 & 2,88 & 8,11 \\
\hline 0,14 & 3 & 2,09 & 0,18 & 0,82 & 12,71 & 4,75 & 1,1 & 1,1 & 5,73 & 3,22 & 7,97 \\
\hline 0,04 & 4 & 0,80 & 0,21 & 1,25 & 6,1 & 5,94 & 0,9 & 0,1 & 6,16 & 2,03 & 7,97 \\
\hline 0,05 & 5 & 0,32 & 0,07 & 1,20 & 9,66 & 6,36 & 0,9 & 0,6 & 6,60 & 1,61 & 7,97 \\
\hline 0,02 & 6 & 0,48 & 0,24 & 1,15 & 7,12 & 4,44 & 1,0 & 1,7 & 4,42 & 3,53 & 7,97 \\
\hline 0,03 & 7 & 0,48 & 0,19 & 1,36 & 10,17 & 3,06 & 0,9 & 2,1 & 3,13 & 4,91 & 7,97 \\
\hline 0,02 & 8 & 0,32 & 0,17 & 1,50 & 1,36 & 1,50 & 0,8 & 2,0 & 1,46 & 6,61 & 8,11 \\
\hline 0,01 & 9 & 0,10 & 0,20 & 1,30 & 3,56 & 2,38 & 0,9 & 1,6 & 2,38 & 5,59 & 7,97 \\
\hline 0,03 & 10 & 0,32 & 0,12 & 1,68 & 3,08 & 2,21 & 0,8 & 0,3 & 2,26 & 5,76 & 7,97 \\
\hline 0,06 & 11 & 0,32 & 0,06 & 2,65 & 1,69 & 1,53 & 0,7 & 1,8 & 1,44 & 6,44 & 7,97 \\
\hline
\end{tabular}




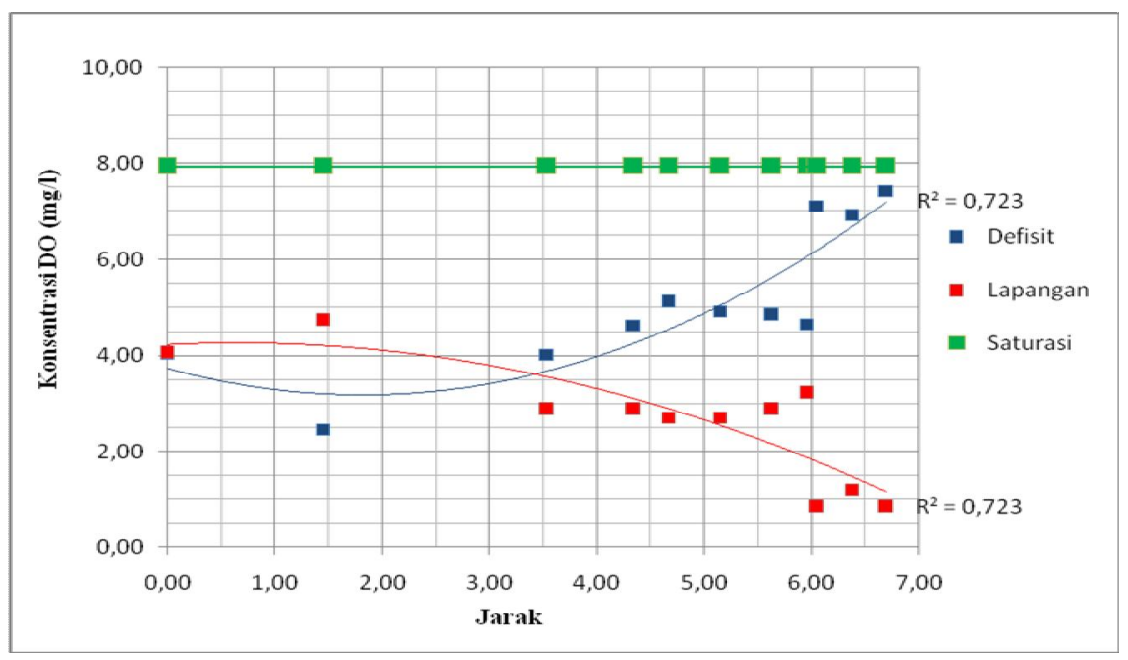

(1) Kondisi Surut

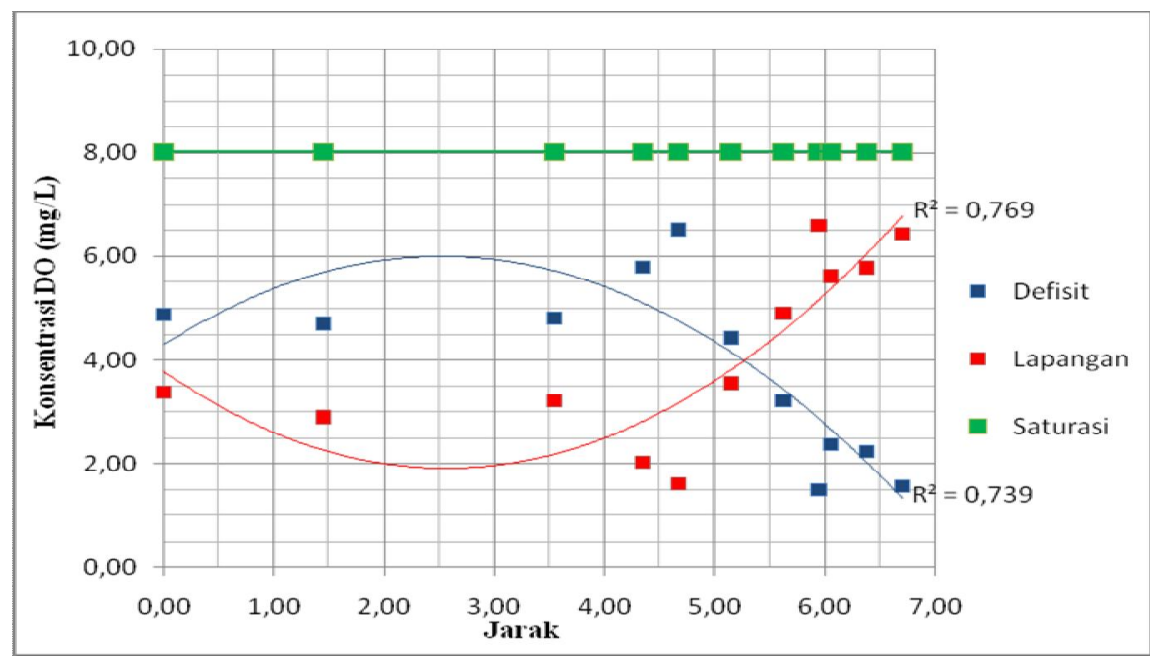

(2) Kondisi Pasang

Gambar 1. Grafik Defisit Oksigen di Saluran Parit Tokaya

Gambar 1 pada kondisi surut menunjukan menurunnya konsentrasi DO ke arah hulu yang diikuti dengan besarnya defisit Oksigen. Sedangkan Gambar 2 pada kondisi pasang menghasilkan bentuk kurva DO hasil pengukuran lapangan yang menyerupai kurva lendutan Oksigen atau sag curve dimana konsentrasi DO kembali naik setelah melewati titik kritis sedangankan defisit Oksigen menurun seiring dengan peningkatan konsentrasi DO. Bentuk grafik yang dihasilkan dari konsentrasi DO per titik sampel akan menghasilkan grafik yang menggambarkan nilai Kr untuk Saluran parit Tokaya. Nilai Kr yang dihasilkan dipengaruhi oleh bentuk penampang saluran serta kecepatan aliran yang mempengaruhi proses reaerasi mengingat kemiringan Saluran Parit Tokaya relatif kecil serta tidak adanya terjunan maupun pergolakan air sehingga aliran air di Parit Tokaya cukup tenang.

Nilai Kr pada kondisi surut dan juga pasang di Saluran Parit Tokaya telah melebihi rentang yang ditetapkan berdasarkan pada KEPM EN NO 110 Tahun 2003. Nilai Kr yang ditetapkan adalah 0,1 - 0,23 untuk sungai kecil dengan aliran balik yang sepadan dengan Saluran Parit Tokaya. Hasil pengukuran menunjukan nilai Kr sebesar 0,07-2,5 yang menunjukan air di Saluran Parit Tokaya masih kekurangan Oksigen. Kondisi ini menunjukan perlunya perbaikan DO. Maka dari itu, perbaikan kualitas air terhadap buangan organik akan dimulai dari nilai Kr pada saat surut sebagai Kr terburuk. Untuk itu, beberapa tindakan akan dilakukan untuk dapat memperbaiki konsentrasi Oksigen di dalam Saluran Parit Tokaya agar biota air yang ada di dalamnya dapat tetap hidup.

Upaya peningkatan nilai Kr dilakukan dengan peningkatan laju aerasi. Peningkatan laju aerasi dapat dengan menimbulkan efek turbulensi melalui aerator. 


\section{Analisis Kecepatan Aliran "Perlu" dengan Meninjau Nilai Kr}

Kurva DO target yang terbentuk menghasilkan nilai Kr yang lebih besar dari kurva DO eksisiting. Nilai $\mathrm{Kr}$ yang dihasilkan adalah 0,1-3,3 pada kondisi surut. Dengan penampang saluran yang sama maka kecepatan yang dibutuhkan oleh saluran pada saat surut di titik satu untuk memenuhi DO target dapat dijelaskan dengan rumus $0^{\prime}$ Connor-Dobbins sebagai berikut:

$$
\begin{aligned}
& k_{r}\left(t^{2} \mathrm{C}\right)=k_{r}\left(20^{\circ} \mathrm{C}\right) \times 1,0238^{i(-20)} \\
& k_{r}\left(20^{\circ} \mathrm{C}\right)-\frac{3,33}{1,024^{i 27-20)}} \\
& k_{m}\left(20^{\circ} \mathrm{C}\right)=1,10 \times 1,0250^{(h)} \\
& k_{r}\left(20^{\circ} \mathrm{C}\right)-2,0
\end{aligned}
$$

Sehingga;

$$
\begin{aligned}
& k_{r}\left(20^{\circ} \mathrm{C}\right)=3,93 \frac{V^{0, \mathrm{I}}}{R^{1, .5}} \\
& V^{0.5}-\left(\frac{R^{1.5} \times k_{r}\left(20^{\circ} \mathrm{C}\right)}{3,93}\right)^{1 / 2} \\
& V^{0,5}=\left(\frac{0,85^{1.5} \times 2,8}{3,93}\right)^{1 / 2} \\
& V^{0,5}=0,75 \mathrm{~m} / \mathrm{s}
\end{aligned}
$$

\begin{tabular}{|c|c|c|c|c|c|c|c|c|c|c|c|c|c|}
\hline $\begin{array}{c}t \\
\text { (hari) }\end{array}$ & Titik & $\begin{array}{c}\mathrm{X} \\
(\mathrm{km})\end{array}$ & $\begin{array}{c}\text { V } \\
\text { "Perlu" } \\
\text { (m/s) }\end{array}$ & $\begin{array}{l}h \\
\text { (m) }\end{array}$ & $\begin{array}{c}\mathrm{T} \\
\left.{ }^{\circ} \mathrm{C}\right)\end{array}$ & $\begin{array}{c}\text { Lo } \\
(\mathrm{mg} / \mathrm{l})\end{array}$ & $\begin{array}{c}\mathrm{Da} \\
(\mathrm{mg} / \mathrm{l})\end{array}$ & $\begin{array}{c}\mathrm{Kd} \\
\left(20^{\circ} \mathrm{C}\right)\end{array}$ & Kd & $\begin{array}{c}\mathrm{Kr} \\
\left(20^{\circ} \mathrm{C}\right)\end{array}$ & $\mathrm{Kr}$ & $\begin{array}{c}D \\
(\mathrm{mg} / \mathrm{l})\end{array}$ & $\begin{array}{c}\text { D0 } \\
\text { Target } \\
(\mathrm{mg} / \mathrm{l})\end{array}$ \\
\hline 0,00 & 1 & 0,00 & 0,75 & 0,85 & 26,0 & 8,14 & 2,05 & 0,8 & 1,1 & 2,8 & 3,33 & 2,05 & 6,06 \\
\hline 0,04 & 2 & 1,45 & 0,40 & 0,68 & 29,0 & 3,39 & 0,95 & 0,9 & 1,3 & 1,1 & 1,33 & 1,08 & 6,74 \\
\hline 0,20 & 3 & 2,09 & 0,12 & 0,75 & 28,0 & 5,08 & 2,95 & 0,8 & 1,2 & 0,1 & 0,10 & 4,00 & 4,88 \\
\hline 0,05 & 4 & 0,80 & 0,19 & 0,75 & 28,0 & 7,63 & 2,95 & 0,8 & 1,2 & 0,2 & 0,25 & 3,36 & 4,88 \\
\hline 0,03 & 5 & 0,32 & 0,15 & 0,70 & 27,0 & 8,14 & 3,26 & 0,9 & 1,2 & 0,1 & 0,17 & 3,49 & 4,71 \\
\hline 0,02 & 6 & 0,48 & 0,32 & 0,60 & 27,0 & 5,42 & 3,26 & 0,9 & 1,3 & 0,8 & 1,00 & 3,32 & 4,71 \\
\hline 0,02 & 7 & 0,48 & 0,36 & 0,70 & 27,0 & 5,08 & 3,09 & 0,9 & 1,2 & 0,8 & 1,00 & 3,14 & 4,88 \\
\hline 0,01 & 8 & 0,32 & 0,29 & 0,50 & 26,0 & 7,63 & 2,89 & 1,0 & 1,3 & 0,9 & 1,10 & 2,98 & 5,22 \\
\hline 0,00 & 9 & 0,10 & 0,67 & 1,10 & 27,0 & 14,24 & 5,13 & 0,7 & 1,0 & 1,5 & 1,80 & 5,14 & 2,84 \\
\hline 0,01 & 10 & 0,32 & 0,61 & 0,90 & 27,0 & 30,51 & 4,79 & 0,8 & 1,1 & 1,7 & 2,00 & 4,93 & 3,18 \\
\hline 0,00 & 11 & 0,32 & 1,03 & 1,50 & 27,0 & 28,47 & 5,13 & 0,6 & 0,9 & 2,3 & 2,67 & 5,17 & 2,84 \\
\hline
\end{tabular}

Data lengkap kecepatan yang harus dicapai untuk memenuhi DO target disajikan dalam Tabel 8 (Hasil analisis, 2012)

Tabel 8. Perubahan kecepatan aliran yang diperlukan untuk mencapai niali Kr Saluran Parit Tokaya

Dari perhitungan Tabel di atas, maka kecepatan aliran yang di perlukan untuk proses swa purifikasi berkisar antara 0,12 m/s - 1,03 m/s.

\section{E. Evaluasi Kecepatan Aliran "Izin"}

Sebagaimana yang telah ditampilkan dalam Tabel 8 dari hasil analisis, kecepatan aliran yang seharusnya adalah berkisar dari 0,12-1,03 $\mathrm{m} / \mathrm{s}$ agar Oksigen terlarut berada pada zona aman sehingga proses swa purifikasi dapat terjadi. Tidak hanya bentuk penampang saluran, kekasaran dinding saluran juga berpengaruh untuk meningkatkan kecepatan aliran di dalam saluran. Di dalam Tabel 9 di tampilkan data kecepatan aliran di Saluran Parit Tokaya yang seharusnya tercapai pada kondisi eksisting berdasarkan persamaan Manning. 
Tabel 9: Daftar Kecepatan Eksisting, Kecepatan Perlu, serta Kecepatan Izin pada saat Surut

\begin{tabular}{|c|c|c|c|c|c|}
\hline \multirow{2}{*}{ Titik } & \multirow{2}{*}{$\begin{array}{l}\text { Lebar Saluran } \\
\text { (m) }\end{array}$} & \multirow{2}{*}{$\begin{array}{l}\text { Kedalaman } \\
\text { (m) }\end{array}$} & \multicolumn{3}{|c|}{ Kecepatan Aliran (m/ s) } \\
\hline & & & Eksisting & Perlu & Izin (M anning) \\
\hline 1 & 5,80 & 0,85 & 0,04 & 0,75 & 0,40 \\
\hline 2 & 5,90 & 0,68 & 0,26 & 0,40 & 0,89 \\
\hline 3 & 7,50 & 0,75 & 0,35 & 0,12 & 0,96 \\
\hline 4 & 8,00 & 0,75 & 0,35 & 0,19 & 0,97 \\
\hline 5 & 11,40 & 0,70 & 0,10 & 0,15 & 0,96 \\
\hline 6 & 9,50 & 0,60 & 0,49 & 0,32 & 0,87 \\
\hline 7 & 10,05 & 0,70 & 0,54 & 0,36 & 0,95 \\
\hline 8 & 14,60 & 0,50 & 0,60 & 0,29 & 0,79 \\
\hline 9 & 11,35 & 1,10 & 0,51 & 0,67 & 1,25 \\
\hline 10 & 11,98 & 0,90 & 0,31 & 0,61 & 0,96 \\
\hline 11 & 8,00 & 1,50 & 0,20 & 1,03 & 1,20 \\
\hline
\end{tabular}

Data kecepatan aliran yang disajikan dalam Tabel 9 menunjukan bahwa kecepatan aliran yang seharusnya dapat dicapai oleh Saluran Parit Tokaya dengan kondisi kontruksi dinding saluran yang ada di lapangan saat ini sudah melebihi kecepatan aliran yang diperlukan untuk proses swa purifikasi di setiap titiknya. Namun banyaknya sampah yang ada di dalam saluran serta tingginya sedimen turut menghambat pergerakan air di dalam saluran sehingga kecepatan aliran menjadi jauh lebih kecil dari kecepatan aliran yang seharusnya bisa dicapai. Kekurangan kecepatan aliran yang cukup jauh untuk mencapai kecepatan aliran yang dibutuhkan untuk proses swa purifikasi maupun kecepatan aliran berdasarkan persamaan Manning, akan dicapai dengan menambahkan efek turbulensi dari aerator sekaligus injeksi Oksigen terlarut ke dalam air agar konsentrasi Oksigen di dalam air memenuhi DO target.

\section{F. Penambahan Aerator untuk Meningkatkan Konsentrasi Oksigen}

Aerator yang digunakan adalah aerator jenis difussi. Kapasitas aerator yang diperlukan untuk menyediakan Oksigen dihitung dengan mempertimbangkan volume bak aerasi (v), kinerja aerator yang diharapkan (N), serta kecepatan pemanfaatan Oksigen $\left(\mathrm{Ro}_{2}\right)$.

Dalam perencanaan ini, secara teoritis jumlah aerator yang seharusnya dipasang di sepanjang saluran parit Tokaya adalah sebanyak 43 buah, namun dengan pertimbangan kondisi di lapangan, yaitu bagian hulu dengan DO yang cukup baik serta jauh dari buangan limbah, maka di daerah hulu antara titik 1 dan titik 2 yang seharusnya dipasang sebanyak 9 buah aerator hanya dipasang satu buah aerator saja sehingga aerator yang akan dipasang di lapangan adalah sebanyak 35 buah. Level daya pada masing-masing aerator bervariasi yang secara detail dapat dilihat pada Tabel 10 (hasil analisis,2012).

Tabel 10. Perhitungan Level Daya M asing-masing Aerator

\begin{tabular}{|c|c|c|c|c|c|c|c|c|c|c|c|c|c|c|}
\hline Titik & $\begin{array}{c}\mathrm{T} \\
\left({ }^{\circ} \mathrm{C}\right)\end{array}$ & $\begin{array}{c}\text { No } \\
\text { (Kg } \\
\mathrm{O}_{2} / \mathrm{kw} \\
\text { h) }\end{array}$ & $\rho$ & $\begin{array}{l}\mathrm{c}^{*} \\
(\mathrm{mg} / \\
\mathrm{I})\end{array}$ & $\begin{array}{c}\mathrm{C} \\
(\mathrm{mg} / \\
\mathrm{I})\end{array}$ & $\alpha$ & $\gamma$ & $\begin{array}{c}\mathrm{N} \\
(\mathbf{k g} \\
\left.\mathrm{O}_{2} / \mathrm{kwh}\right)\end{array}$ & $\begin{array}{c}V \\
\left(\mathrm{~m}^{3}\right)\end{array}$ & $\begin{array}{c}A \\
\left(\mathrm{~m}^{2}\right)\end{array}$ & $\begin{array}{c}\mathrm{BO}_{2} \\
(\mathrm{~g} \\
\mathrm{O}_{2} / \mathrm{m}^{2} . \\
\mathrm{hr})\end{array}$ & $\begin{array}{c}\mathrm{RO}_{2} \\
(\mathrm{Kg} \\
\left.\mathrm{O}_{2} / \mathrm{jam}\right)\end{array}$ & $\begin{array}{l}P \\
(W / \\
\left.m^{3}\right)\end{array}$ & $\begin{array}{l}\text { Jumlah } \\
\text { Aerator }\end{array}$ \\
\hline 1 & 28,6 & 0,8 & 1 & 7,59 & 6,06 & 0,7 & 1,23 & 0,11 & 739,5 & 870,0 & 3,3 & 0,001 & 39 & 1 \\
\hline 2 & 28,3 & 0,8 & 1 & 7,62 & 6,74 & 0,7 & 1,22 & 0,07 & 601,8 & 885,0 & 3,3 & 0,001 & 84 & 14 \\
\hline 3 & 28,0 & 0,8 & 1 & 7,66 & 4,88 & 0,7 & 1,21 & 0,21 & 843,7 & 1125,0 & 4,2 & 0,002 & 24 & 6 \\
\hline 4 & 27,7 & 0,8 & 1 & 7,70 & 4,88 & 0,7 & 1,20 & 0,21 & 900,0 & 1200,0 & 4,4 & 0,002 & 24 & 2 \\
\hline 5 & 27,0 & 0,8 & 1 & 7,79 & 4,71 & 0,7 & 1,18 & 0,22 & 1197,0 & 1710,0 & 6,0 & 0,002 & 23 & 3 \\
\hline 6 & 27,0 & 0,8 & 1 & 7,79 & 4,71 & 0,7 & 1,18 & 0,22 & 855,0 & 1425,0 & 5,0 & 0,002 & 26 & 3 \\
\hline 7 & 26,5 & 0,8 & 1 & 7,86 & 4,88 & 0,7 & 1,17 & 0,21 & 1055,2 & 1507,5 & 5,2 & 0,002 & 23 & 2 \\
\hline 8 & 26,6 & 0,8 & 1 & 7,84 & 5,22 & 0,7 & 1,17 & 0,19 & 1095,0 & 2190,0 & 7,6 & 0,002 & 37 & 1 \\
\hline 9 & 27,0 & 0,8 & 1 & 7,79 & 2,84 & 0,7 & 1,18 & 0,36 & 1872,7 & 1702,5 & 6,0 & 0,004 & 9 & 1 \\
\hline 10 & 27,0 & 0,8 & 1 & 7,79 & 3,18 & 0,7 & 1,18 & 0,33 & 1617,3 & 1797,0 & 6,3 & 0,003 & 12 & 1 \\
\hline 11 & 27,0 & 0,8 & 1 & 7,79 & 2,84 & 0,7 & 1,18 & 0,36 & 1800,0 & 1200,0 & 4,2 & 0,004 & 7 & 1 \\
\hline
\end{tabular}


Jenis Aerator yang akan digunakan dalam perencanaan ini adalah jenis aerator diffuser seperti yang terlihat pada Gambar 3.

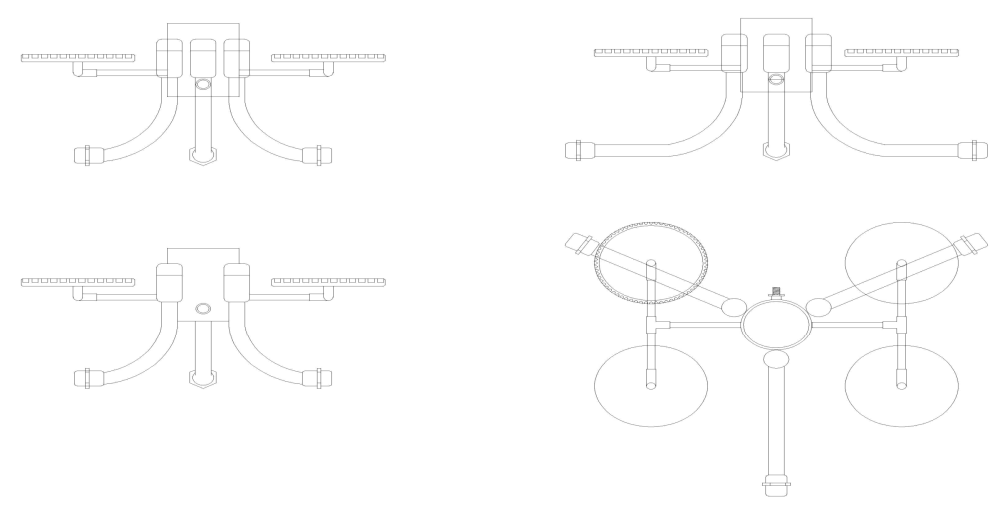

Gambar 3. Aerator Jenis Diffusi

\section{KESIM PULAN}

Berdasarkan hasil dan analisis dalam studi di saluran Parit tokaya maka dapat disimpulkan bahwa, pada saat pasang

1. Saluran Parit Tokaya telah mampu melakukan proses swa purifikasi, namun ketika surut swa purifikasi tidak terjadi sehingga pada kondisi surut perlu dilakukan upaya perbaikan konsentrasi DO.

2. faktor yang mempengaruhi proses swa purifikasi di dalam saluran, diantaranya adalah nilai koefisien rearasi $(\mathrm{Kr})$ yang dipengaruhi oleh turbulensi aliran. Nilai $\mathrm{Kr}$ yang diperlukan untuk proses swa purifikasi di Saluran Parit Tokaya pada kondisi surut adalah berkisar antara 0,10-3,3.

3. penambahan aerator di Saluran parit Tokaya adalah sebanyak 35 buah untuk meningkatkan konsentrasi DO di dalam saluran dengan level daya yang bervariasi yaitu dari 7-84 W/ $\mathrm{m}^{3}$.

Dalam kesempatan ini, penulis menyampaikan terima kasih yang setulus-tulusnya kepada:Bapak Winardi, ST.,MT., selaku Dosen Pembimbing Utama,

Bapak Kiki Prio Utomo, M.Sc., selaku Dosen Pembimbing Kedua

\section{Referensi}

Boyd, C.E. 1979. Water Quality in Warmwater Fish Ponds. Alabama Agricultural Experiment Station, Auburn Univercity, Alabama, USA.

Davis, Mackenzie $L$ and David A. Cornwell. 1991. Introduction to environmental engineering $2^{\text {nd }}$ edition - International edition. McGraw-Hill. Singapore.

Droste, ronald L. 1977. Theory and practice of water and waswater treatment. New York: John Wiley $\&$ sons.

M oersidik. 2008. Load Capacity Study of Ciliwung Watershed.

Peavy, Howard S, Donal R. Rowe, George Tchobanoglous. 1985. Environmental engineering International edition. McGraw-Hill. Singapore.

Rich, Linvil G. 2001. Sistem Pengolahan Air Limbah Pemeliharaan Rendah, M ekanikal Sederhana. Bandung: Institut Teknologi Bandung. 